\title{
The Relationship between Health-Promoting Behaviors and Resilience in Patients with Chronic Kidney Disease
}

\author{
Li-Ching Ma, ${ }^{1}$ Hong-Jer Chang, ${ }^{2}$ Yueh-Min Liu, ${ }^{1,2}$ Hsiang-Li Hsieh, ${ }^{1}$ Lan Lo, \\ Mei-Yu Lin, ${ }^{3}$ and Kuo-Cheng $\mathrm{Lu}^{3}$ \\ ${ }^{1}$ Department of Nursing, Cardinal Tien Hospital, New Taipei, Taiwan \\ ${ }^{2}$ Graduate Institute of Long-Term Care, National Taipei College of Nursing, Taipei, Taiwan \\ ${ }^{3}$ Division of Nephrology, Department of Medicine, Cardinal Tien Hospital, School of Medicine, \\ Fu-Jen Catholic University, 362 Chung-Cheng Road, Hsin-Tien, New Taipei, Taiwan
}

Correspondence should be addressed to Kuo-Cheng Lu; kuochenglu@gmail.com

Received 7 January 2013; Accepted 29 January 2013

Academic Editors: C. Varricchio and D. Wynaden

Copyright (C) 2013 Li-Ching Ma et al. This is an open access article distributed under the Creative Commons Attribution License, which permits unrestricted use, distribution, and reproduction in any medium, provided the original work is properly cited.

\begin{abstract}
This cross-sectional research study explored differences in health-promoting behavior and resilience among three groups of chronic kidney disease patients (high-risk, early chronic kidney disease; early CKD and pre-end stage renal disease; pre-ESRD) treated at the Nephrology outpatient clinic in northern Taiwan. A total of 150 CKD outpatients were interviewed using structured questionnaires including a CKD Health to Promote Lifestyle Scale, and resilience scale. We found that the pre-ESRD group had lower resilience than either high-risk or early CKD groups. Factors affecting pre-ESRD resilience were gender, occupational status, diabetes and health-promoting behaviors. Factors affecting resilience of the high-risk group included level of education and health-promoting behaviors while factors affecting resilience in the early CKD group involved whether they are employed and health promoting behaviors. A significant positive correlation was found between health promoting behavior and resilience in all study subjects. Multiple regression analysis found that factors which could effectively predict resilience in patients at high-risk for CKD were gender, whether the patient had a job, nutrition, self-actualization, and stress level, accounting for $69.7 \%$ of the variance. Therefore, nursing education should focus on health promotion advocacy throughout the life of not only patients but also their families.
\end{abstract}

\section{Introduction}

According to the 2009 National Institutes of Health Survey, performed on a prospective cohort of 462,293 subjects in Taiwan, approximately $12 \%$ of subjects surveyed suffered from some form of chronic kidney disease (CKD). This survey also found that high blood pressure, diabetes, age over 65 years, a family history of disease, failure to give sufficient attention to health promotion, and other risk factors were responsible for the rise in the number of CKD cases annually $[1,2]$. Once patients are on dialysis, they are exposed to the physical, psychological and social discomforts of the treatment [3]. In addition, there are secondary physical, psychological, and social burdens on their family members [4].
Resilience of individuals can mitigate the pressure caused by the negative impact of chronic disease. Intelligence, interpersonal skills, self-efficiency, positive response to the problem, and social support networks can all improve the patient's response to illness [5]. CKD patients and their families need to understand the importance of resilience, and medical personnel need to be educated in this area as well, in order to provide timely correct messaging that will help reduce the stress and frustration associated with chronic disease. An important factor affecting resilience in patients with CKD is the failure to give sufficient attention to health-promoting behaviors such as good nutrition, selfrealization, stress reduction, proper sports, and fitting leisure time. Ignorance of such health promoting behaviors can 
lead to increased morbidity and mortality and even suicidal behavior $[6,7]$.

When CKD progresses to end stage renal disease (ESRD), patients must receive dialysis treatment to survive, and they are often prone to emotions such as a feeling of helplessness, depression, and fear. In a study by Yeh et al. [8], 12.3\% of patients with CKD were in a depressed state as their family members assumed the role of primary caregiver, primary caregiver which altered their domesticity. According to a study by Liu et al. [9], more attention should be paid to the needs of families to assist in the prevention or treatment of disease. Since 2003, the Bureau of National Health Insurance (BNHI) in Taiwan, in response to the growing number of patients with ESRD and the subsequent heavy financial burden placed on BNHI, has implemented several pre-ESRD preventive plans and patient education programs (including high-risk health management) to actively promote the health of high-risk and kidney transplant patients. In addition, they sought to improve the health of family members of such high-risk groups, including spouses, parents, children, and siblings. Early detection and active treatment may effectively reduce the incidence of ESRD and enhance health management capabilities of such high-risk groups, thereby possibly increasing resilience.

Therefore, we strive to understand the effect of resilience on the management of such high-risk patients and their families in order to provide medical personnel with sufficient information to improve the welfare of CKD patients.

\section{Methods}

2.1. Study Design and Population. The study was approved by the institutional review board (CTH-100-3-5-007). Informed written consent was obtained from all subjects or their guardians after permission was obtained.

This study compared the differences in health-promoting behavior and resilience among three groups of CKD patients (high risk, early CKD, and pre-ESRD) treated at the nephrology outpatient clinic (OPD) in northern Taiwan. A crosssectional descriptive design was used. CKD patients and their families (as a high-risk group) were recruited from April 1 to December 31, 2011, and divided into three groups by using the following inclusion criteria: (1) the high-risk group of CKD; (2) early CKD group stages 1, 2, and 3a: eGFR $>45 \mathrm{~mL} / \mathrm{min} / 1.73 \mathrm{~m}^{2}$ (by MDRD 4 variables equation); (3) pre-ESRD group involving CKD stages $3 \mathrm{~b}, 4$, and 5: eGFR $<45 \mathrm{~mL} / \mathrm{min} / 1.73 \mathrm{~m}^{2}$. Patients were also required to speak either Mandarin, Taiwanese, or Hakka language and had to be willing to sign a consent form.

2.2. Data Collection Procedures. After the researchers explained the study to the patients, $160 \mathrm{CKD}$ patients who were recruited from the Nephrology OPD from Cardinal-Tien Hospital in New Taipei city, Taiwan, were pretested in face-toface interviews. These interviews lasted approximately 30 to 60 minutes, including the time to fill out the resilience scale, record demographic characteristics and laboratory data from the medical records, and distribute additional questionnaires.
Ten patients were excluded due to other illness with resultant 150 patients enrolled in the study.

To estimate the number of samples, according to the $G$ power 3.0 software, alpha was set at .05 , the statistical power was set at .80, effect (effect size) was set at .25 (small to medium intensity), and the estimated number of samples was estimated at 120 . Since a total of 150 patients were actually enrolled, this increased the power to .92 .

2.3. GFR Calculation. This study used a structured questionnaire as a research tool which contained demographic characteristics, disease characteristics, health promotion lifestyle scale, and a resilience scale.

(1) The demographic characteristics included gender, age, educational level, and occupation.

(2) The disease characteristics included serum creatinine level, glomerular filtration rate (GFR), the level of CKD, and history of either high blood pressure or diabetes.

The GFR formula, adapted from the simplified MDRD (Modification of Diet in Renal disease) formula, was used as follows:

[eGFR $\mathrm{mL} / \mathrm{min} / 1.73 \mathrm{~m}^{2}$ (Simplified MDRD) $=186 \times \mathrm{Scr}$ $-1.154 \times$ Age $-0.203 \times 0.742$ (if female) $\times 1.212$ (if black patient)].

(3) Health promotion lifestyle scale. Health promoting lifestyle was measured using the CKD Health to Promote Lifestyle Scale, which was considered valid and reliable. The validity and reliability of the original Health Promoting Lifestyle Scale were assessed using a sample of 920 subjects with a resulting Cronbach's $\alpha$ of .92 [10]. The CKD Health Promoting Lifestyle Scale comprised 40 items that assessed the following six subsets of lifestyle: (1) nutritional (5 questions); (2) health responsibility (8 questions); (3) self-actualization (8 questions); (4) interpersonal support (6 questions); (5) sports and leisure (6 questions); (6) stress management (7 questions).

To validate the content, two nephrologists, a nurse specialist, a hemodialysis center head nurse, and a CKD health education management expert rated the questionnaires based on topic clarity and usability ratings, with a resulting content validity index value (CVI) of .90, consistent with a Cronbach's $\alpha$ of .93 , with subsets between .79 and -.90 . The measuring instrument used to obtain the frequency of reported lifestyle was a self-reporting Likert scale with a four-point response format of "never, sometimes, usually, and always," with a rating score ranging from 0 to 3 , and a total score of 0 to 120 (with higher scores indicating improved health promotion lifestyle).

(4) Resilience scale. Wagnild and Young [11] developed the resilience scale questionnaire used in this study. This scale was translated into Chinese by $\mathrm{Li} \mathrm{[12]} \mathrm{and} \mathrm{the} \mathrm{Chinese}$ version of the questionnaire was used in this study. The scale consisted of 25 questions covering the following five levels: (1) meaning of life (7 questions); (2) calm mind areas (6 questions); (3) retains confidence areas (6 questions); (4) indomitable spirit of the scope (3 questions); (5) acceptance of the existence of solitude areas ( 3 questions). One point was used by patients to "strongly disagree" and up to seven points 
to "strongly agree" in order to reflect the level most in line with the current situation, for a total score of 25-175 points (with higher scores indicating better resilience). Li [12] tested 329 college students with a resulting Cronbach's $\alpha$ value of .90; Wagnild and Young [11] used the scale as a test object for older women and achieved a Cronbach's $\alpha$ value of .94. Margaret [13] tested 277 elderly subjects with a resulting Cronbach's $\alpha$ value of .94. In this study, we achieved a Cronbach's $\alpha$ value of .89, which indicated that this scale had good reliability and validity for assessing patients' resilience.

2.4. Statistical Analysis. Statistical analysis included descriptive statistics (frequency, percentage, mean, and standard deviation) and inferential statistics that use independent samples $t$-test and one way analysis of variance (ANOVA) to determine the differences in participant perceptions of health promotion behavior, and resilience. Correlation and multiple regression analysis between demographic data, disease characteristics, health-promoting behavior subgroup (subset) and resilience were explored further. A $P$ value less than 0.05 was considered statistically significant. All statistical analysis was performed using SPSS software (SPSS Version 19).

\section{Results}

3.1. Comparative Demographics, Disease Characteristics and Resilience of the Study Sample. Out of a total of 150 participants, 40 were high-risk group subjects. The average age of the high-risk group was $59.9 \pm 14.6$ years and their average GFR was $83.3 \mathrm{~mL} / \mathrm{min} / 1.73 \mathrm{~m}^{2}$. The average age of the 50 participants in the early CKD group was $65.1 \pm 13.6$ years and their average GFR was $75.6 \mathrm{~mL} / \mathrm{min} / 1.73 \mathrm{~m}^{2}$. The preESRD group included 60 participants with an average age of $68.9 \pm 14.6$ years and an average GFR of $21.8 \mathrm{~mL} / \mathrm{min} / 1.73 \mathrm{~m}^{2}$. Among the 150 subjects, most were married, unemployed, and had diabetes.

3.1.1. Difference in Resilience within Each Study Group (Table 1). In high-risk groups, patients with higher education level (above high school) have a higher resilience score when compared with patients with lower education levels $(P<.05)$. In both early CKD and pre-ESRD groups, employed patients have a higher resilience score than un employed patients $(P<$ .05 versus $P<.001$ resp.). In pre-ESRD group, patients with diabetes have a lower resilience score when compared with patients without diabetes $(P<.01)$.

\subsubsection{Difference in Resilience among the Three Study Groups.} The resilience among the three groups was influenced by demographic characteristics. Chi-square analysis of the three groups found that various educational levels $\left(\chi^{2}=7.714, P<\right.$ $.05)$, with or without an occupation $\left(\chi^{2}=6.818, P<.05\right)$ and the presence or absence of diabetes $\left(\chi^{2}=16.617, P<.001\right)$, were significantly influenced on resilience score.

3.2. Comparative Resilience of the Study Subjects. For all subjects, the average resilience was $139.0 \pm 21.1$. Post hoc comparisons (Scheffe test) showed that the early CKD group's resilience score was higher than the other two groups' scores. The lowest score was found in the pre-ESRD patients $(130.7 \pm$ 22.1) (Table 2).

3.3. Comparison of Health Promotion Behavior of the Study Subjects. The overall health-promoting behaviors among different groups were significantly different $(F=6.982$, $P<.01)$. The health promotion behavior score of the pre-ESRD group was significantly lower than the other two groups. The sequencing of average score (from high to low) was nutrition, self-actualization, interpersonal support, stress management, health responsibility, and sports and leisure levels. The sequencing of average score (from high to low) of the early CKD group was nutrition, interpersonal support, self-actualization, stress management, health responsibility, and sports and leisure level. The sequencing of average score (from high to low) of the high-risk group was self-realization, stress management, nutrition, health responsibility, interpersonal support, and sports and leisure levels. Among the three groups, nutrition, self-actualization, interpersonal support, sports and leisure, and stress management levels were significantly different $(P<.01)$ (Tables 3 and 4$)$.

\subsection{Correlation between Demographic Characteristics, Disease} Characteristics, Health-Promoting Behavior, and Resilience. Table 5 shows that in the high-risk group, the resilience strongly correlated with education level, nutrition, selfrealization, and stress management. In the early CKD group, the resilience correlated with, whether or not the subject was employed, nutrition, self-realization, interpersonal support, sports and leisure, and stress management levels. In the preESRD group, the resilience correlated with gender, whether or not the subject was employed, diabetes, nutrition, selfrealization, interpersonal support, sports and leisure, and stress management levels.

3.5. Evaluating the Predictive Variables of the Resilience. All the resilience variables were entered into the regression equation to advance into a set of virtual variables for each reference group. The results of the multiple regression analysis $(F=$ 28.817, $P<.001)$ found that gender, presence or absence of an occupation, nutrition level, self-actualization level, and stress management level were the variables that could meaningfully predict resilience and were found to explain $69.7 \%$ of the total variance. From standardized regression coefficient $\beta$ value, stress management level had the strongest explanatory power $(\beta=.349)$. The second strongest was self-actualization level. Under the control of other variables, stress management level $(B=1.794, t=4.582, P<$ .001) significantly influences the resilience with each one unit increase in stress management accompanied by an increase in 1.794 units of resilience. Other variables such as gender, presence or absence of an occupation, nutrition level, and self-actualization level variables also reached statistically significance (Table 6). 
TABLE 1: Difference in resilience between population characteristics and disease characteristics among study groups $(N=150)$.

\begin{tabular}{|c|c|c|c|c|c|c|c|c|c|c|c|c|c|}
\hline \multirow{2}{*}{ Variables } & \multicolumn{4}{|c|}{ High-risk group $N=40$} & \multicolumn{4}{|c|}{ Early CKD group $N=50$} & \multicolumn{4}{|c|}{ Pre-ESRD group $N=60$} & \multirow{2}{*}{$x^{2}$} \\
\hline & $n$ & $(\%)$ & Mean \pm SD & $t$ values & $n$ & $(\%)$ & Mean \pm SD & $t$ values & $n$ & $(\%)$ & Mean \pm SD & $t$ values & \\
\hline Gender & & & & .461 & & & & 1.847 & & & & $2.756^{* *}$ & $\chi^{2}=5.193$ \\
\hline Male & 16 & 40.0 & $143.56 \pm 13.18$ & & 32 & 64 & $150.56 \pm 17.50$ & & 33 & 55 & $137.67 \pm 19.07$ & & \\
\hline Female & 24 & 60.0 & $141.88 \pm 9.98$ & & 18 & 36 & $138.39 \pm 29.23$ & & 27 & 45 & $122.37 \pm 23.12$ & & \\
\hline Education level & & & & $-2.276^{*}$ & & & & -1.852 & & & & -1.258 & $\chi^{2}=7.714^{*}$ \\
\hline$\leq$ junior school & 16 & 40.0 & $137.81 \pm 10.90$ & & 24 & 48 & $140.08 \pm 19.18$ & & 40 & 66.7 & $128.25 \pm 19.86$ & & \\
\hline$\geq$ high school & 24 & 60.0 & $145.71 \pm 10.51$ & & 26 & 52 & $151.81 \pm 24.95$ & & 20 & 33.3 & $135.85 \pm 26.01$ & & \\
\hline Marital status & & & & -1.225 & & & & .682 & & & & -1.047 & $\chi^{2}=.506$ \\
\hline Single & 7 & 17.5 & $137.86 \pm 9.94$ & & 11 & 22 & $150.36 \pm 17.41$ & & 14 & 23.3 & $125.36 \pm 28.16$ & & \\
\hline Married & 33 & 82.5 & $143.55 \pm 11.38$ & & 39 & 78 & $145 \pm 24.31$ & & 46 & 76.7 & $132.43 \pm 20.09$ & & \\
\hline Occupation & & & & .09 & & & & $2.422^{*}$ & & & & $4.479^{* * *}$ & $\chi^{2}=6.818^{*}$ \\
\hline Yes & 8 & 20.0 & $142.88 \pm 9.49$ & & 20 & 40 & $154.30 \pm 12.15$ & & 12 & 20 & $147.33 \pm 11.46$ & & \\
\hline No & 32 & 80.0 & $142.47 \pm 11.76$ & & 30 & 60 & $140.77 \pm 16.74$ & & 48 & 80 & $126.65 \pm 22.34$ & & \\
\hline Diabetes & & & & -1.469 & & & & .149 & & & & $-2.931^{* *}$ & $\chi^{2}=16.617^{* * *}$ \\
\hline Yes & 10 & 25.0 & $137.78 \pm 9.92$ & & 9 & 18 & $147.22 \pm 18.19$ & & 31 & 51.7 & $123.19 \pm 22.91$ & & \\
\hline No & 30 & 75.0 & $143.94 \pm 11.38$ & & 41 & 82 & $145.95 \pm 24.02$ & & 29 & 48.3 & $138.90 \pm 18.48$ & & \\
\hline Hypertension & & & & .816 & & & & -.130 & & & & 1.689 & $\chi^{2}=5.821$ \\
\hline Yes & 3 & 7.5 & $146.4 \pm 12.18$ & & 17 & 34 & $145.59 \pm 21.45$ & & 18 & 30 & $138.06 \pm 20.47$ & & \\
\hline No & 37 & 92.5 & $142 \pm 11.17$ & & 33 & 66 & $146.48 \pm 23.96$ & & 42 & 70 & $127.67 \pm 22.37$ & & \\
\hline
\end{tabular}

High-risk group: the families of CKD patients.

Early CKD group: GFR $>45 \mathrm{~mL} / \mathrm{min} / 1.73 \mathrm{~m}^{2}$.

Pre-ESRD group: GFR $<45 \mathrm{~mL} / \mathrm{min} / 1.73 \mathrm{~m}^{2}$.

${ }^{*} P<.05,{ }^{* *} P<.01$, and ${ }^{* * *} P<.001$.

Statistical methods: descriptive statistics, $t$ tests (within group), and $\chi^{2}$ tests (between groups).

TABLE 2: Difference in resilience among study groups $(N=150)$.

\begin{tabular}{lcccccc}
\hline Variables & $N$ & Mean & Standard deviation & Minimum & Maximum & $F$ value \\
\hline All & 150 & 139.05 & 21.171 & 49 & 171 & $8.788^{* * *}$ \\
High-risk group & 40 & 142.55 & 11.234 & 110 & 164 & Early CKD group $>$ \\
Early CKD group & 50 & 146.18 & 22.918 & 50 & 171 & High-risk group $>$ \\
Pre-ESRD group & 60 & 130.78 & 22.170 & 49 & 169 & Pre-ESRD group \\
\hline
\end{tabular}

High-risk group: the families of CKD patients.

Early CKD group: GFR $>45 \mathrm{~mL} / \mathrm{min} / 1.73 \mathrm{~m}^{2}$.

Pre-ESRD group: GFR $<45 \mathrm{~mL} / \mathrm{min} / 1.73 \mathrm{~m}^{2}$.

${ }^{*} P<.05,{ }^{* *} P<.01$, and ${ }^{* * *} P<.001$.

Statistical methods: descriptive statistics, one way ANOVA.

TABLE 3: Difference in subgroups of health promotion behavior among study groups $(N=150)$.

\begin{tabular}{|c|c|c|c|c|c|}
\hline Variables & $\begin{array}{c}\text { All } \\
N=150 \\
\text { Mean } \pm \text { Standard } \\
\text { deviation }\end{array}$ & $\begin{array}{l}\text { High-risk group } \\
N=40 \\
\text { Mean } \pm \text { Standard } \\
\text { deviation }\end{array}$ & $\begin{array}{c}\text { Early CKD group } \\
N=50 \\
\text { Mean } \pm \text { Standard } \\
\text { deviation }\end{array}$ & $\begin{array}{l}\text { Pre-ESRD group } \\
N=60 \\
\text { Mean } \pm \text { Standard } \\
\text { deviation }\end{array}$ & $F$ value \\
\hline Nutrition & $10.94 \pm 2.742$ & $12.27 \pm 2.375$ & $11.24 \pm 2.544$ & $9.8 \pm 2.698$ & $11.691^{* * *}$ \\
\hline Health responsibility & $13.47 \pm 4.587$ & $13.65 \pm 4.638$ & $14.12 \pm 4.623$ & $12.8 \pm 4.509$ & 1.175 \\
\hline Self-actualization & $17.49 \pm 4.587$ & $19.38 \pm 4.210$ & $18.24 \pm 5.255$ & $15.6 \pm 4.951$ & $8.097^{* * *}$ \\
\hline Interpersonal support & $12.51 \pm 3.874$ & $13.27 \pm 3.449$ & $13.18 \pm 3.921$ & $11.43 \pm 3.684$ & $4.023^{* *}$ \\
\hline Sports and leisure & $5.34 \pm 3.941$ & $7.35 \pm 4.073$ & $4.8 \pm 3.870$ & $4.45 \pm 3.466$ & $7.868^{* *}$ \\
\hline Stress management & $14.15 \pm 4.119$ & $15.4 \pm 2.734$ & $14.64 \pm 4.663$ & $12.92 \pm 4.126$ & $5.159^{* *}$ \\
\hline Total (health promotion behavior) & $73.83 \pm 18.909$ & $80.47 \pm 15.733$ & $76.32 \pm 19.845$ & $67.32 \pm 18.275$ & $6.982^{* *}$ \\
\hline
\end{tabular}

High-risk group: the families of CKD patients.

Early CKD group: GFR $>45 \mathrm{~mL} / \mathrm{min} / 1.73 \mathrm{~m}^{2}$.

Pre-ESRD group: GFR $<45 \mathrm{~mL} / \mathrm{min} / 1.73 \mathrm{~m}^{2}$.

${ }^{*} P<.05,{ }^{* *} P<.01$, and ${ }^{* * *} P<.001$.

Statistical methods: descriptive statistics, one way ANOVA. 
TABLE 4: Average scores and order of subets of health promotion behavior $(N=150)$.

\begin{tabular}{|c|c|c|c|c|c|c|c|}
\hline \multirow{3}{*}{ Variables } & \multirow{3}{*}{ Number of questions } & \multirow{2}{*}{\multicolumn{2}{|c|}{$\begin{array}{l}\text { High-risk group } \\
\qquad N=40\end{array}$}} & \multirow{2}{*}{\multicolumn{2}{|c|}{$\begin{array}{l}\text { Early CKD group } \\
\qquad N=50\end{array}$}} & \multirow{2}{*}{\multicolumn{2}{|c|}{$\begin{array}{l}\text { Pre-ESRD group } \\
\qquad N=60\end{array}$}} \\
\hline & & & & & & & \\
\hline & & Average & Sequencing & Average & Sequencing & Average score & Sequencing \\
\hline Nutrition & 5 & 2.454 & 3 & 2.248 & 1 & 1.960 & 1 \\
\hline Health responsibility & 8 & 1.706 & 4 & 1.765 & 5 & 1.600 & 5 \\
\hline Self-actualization & 8 & 3.230 & 1 & 2.280 & 3 & 1.950 & 2 \\
\hline Interpersonal support & 6 & 1.659 & 5 & 2.197 & 2 & 1.905 & 3 \\
\hline Sports/leisure & 6 & 1.050 & 6 & 0.800 & 6 & 0.742 & 6 \\
\hline Stress management & 7 & 2.570 & 2 & 2.091 & 4 & 1.846 & 4 \\
\hline
\end{tabular}

High-risk group: the families of CKD patients.

Early CKD group: GFR $>45 \mathrm{~mL} / \mathrm{min} / 1.73 \mathrm{~m}^{2}$.

Pre-ESRD group: GFR $<45 \mathrm{~mL} / \mathrm{min} / 1.73 \mathrm{~m}^{2}$.

${ }^{*} P<.05,{ }^{* *} P<.01$, and ${ }^{* * *} P<.001$.

Statistical methods: descriptive statistics.

TABLE 5: Correlation between resilience and demographic characteristics, disease characteristics, and subgroups of health-promoting behavior $(N=150)$.

\begin{tabular}{lccc}
\hline & \multicolumn{3}{c}{ Resilience scores } \\
Variables & $\begin{array}{c}\text { High-risk } \\
\text { group } \\
N=40\end{array}$ & $\begin{array}{c}\text { Early CKD } \\
\text { group }\end{array}$ & $\begin{array}{c}\text { Pre-ESRD } \\
\text { group }\end{array}$ \\
& $r$ & $r=50$ & $N=60$ \\
\hline Gender & -.075 & -.239 & $-.345^{* *}$ \\
Education level & $.349^{*}$ & .244 & .163 \\
Occupation & -.015 & $-.282^{*}$ & $-.377^{* *}$ \\
Diabetes & .232 & -.015 & $.358^{* *}$ \\
Nutrition & $.406^{* *}$ & $.665^{* *}$ & $.443^{* *}$ \\
Self-actualization & $.551^{* *}$ & $.820^{* *}$ & $.690^{* *}$ \\
Interpersonal support & .257 & $.736^{* *}$ & $.533^{* *}$ \\
Sports/leisure & .193 & $.443^{* *}$ & $.419^{* *}$ \\
Stress management & $.379^{*}$ & $.769^{* *}$ & $.680^{* *}$ \\
\hline
\end{tabular}

High-risk group: the families of CKD patients.

Early CKD group: GFR $>45 \mathrm{~mL} / \mathrm{min} / 1.73 \mathrm{~m}^{2}$.

Pre-ESRD group: GFR $<45 \mathrm{~mL} / \mathrm{min} / 1.73 \mathrm{~m}^{2}$.

${ }^{*} P<.05,{ }^{* *} P<.01$, and ${ }^{* * *} P<.001$.

Statistical methods: correlation analysis.

\section{Discussion}

We found that resilience in the pre-ESRD group was lower than the other two groups. In the pre-ESRD patient group, the presence of diabetes also was higher than the other two groups. These patients required long-term dependence on drugs and diet to control the disease, which limited activities and may have increased psychological burden, causing the resilience scores to drop. Similarly, the study by Margaret [13] found that psychological dysfunction reduced resilience. Therefore, health problems related to the pre-ESRD group of patients require more attention from health care providers.

When health-promoting behaviors were compared, the pre-ESRD group scored lower than the other two groups. This may be due to the older age and more diabetes in the pre-ESRD group. In the nutrition subset of health promotion behavior, the early CKD group and pre-ESRD group performed better than high-risk group. Regarding the nutrition levels, the early CKD group and pre-ESRD group were provided appropriate amounts of protein, and low phosphorus, low potassium, but limited amounts of water and pickled foods. The high rate of implementation of this type of nutrition may be secondary to the establishment of CKD health education clinics in our hospital since 2005 . Patients with kidney disease were provided health knowledge by a physician, nutritionist, and educator, who gave nursing advice and diet education along with regular monitoring of blood biochemistry values. Previous studies also demonstrated the importance of good nutrition and healthy lifestyle in maintaining renal function in CKD patients [14]. Powe et al. [15] also recommended that patients should implement a health promoting lifestyle to avoid diseases and their complications.

Regarding self-actualization levels, the high-risk group scored better than the other two groups. In the study by Liu et al. [9], the families who cared for hemodialysis patients for more than three years understood the unique demands of the disease and accepted the impact of the disease on their own lives, resulting in better self-actualization levels.

The level of sports and leisure was the worst healthpromoting behaviors which are a common phenomenon present in all countries [16]. In all our study groups, sports and leisure levels subset of health-promoting behaviors was below average. The mean age of CKD and pre-ESRD subjects were older than 65 years in our study, affecting the physical strength to engage in sports and leisure activities. Therefore, the sports and leisure scores were lower compared to the high-risk group of patients.

A study by Mary et al. [17] showed an increase in resilience after a four-week resilience course. Thus, the determinant factors of resilience need to be explored. Our results showed that the three groups shared common predictable resilience factors with respect to gender and occupational status. The nutrition, self-actualization, and stress management subsets of health promotion behaviors were found to predict 
TABLE 6: Regression analysis of resilience $(N=150)$.

\begin{tabular}{|c|c|c|c|c|c|c|c|}
\hline \multirow{2}{*}{ Predictive variables } & \multicolumn{2}{|c|}{ Unstandardized coefficient } & \multirow{2}{*}{$\begin{array}{c}\text { Standardized coefficients } \\
\beta \text { distribution }\end{array}$} & \multirow{2}{*}{$t$ values } & \multirow{2}{*}{$P$} & \multirow{2}{*}{$R^{2}$} & \multirow{2}{*}{ Adjusted $R^{2}$} \\
\hline & The estimated value of the $B$ & Standard error & & & & & \\
\hline Gender & -5.892 & 2.178 & -.139 & -2.705 & .008 & & \\
\hline Occupation & -7.152 & 2.493 & -.150 & -2.869 & .005 & & \\
\hline Nutrition & 1.227 & .509 & .159 & 2.410 & .017 & & \\
\hline Self-actualization & 1.214 & .361 & .292 & 3.360 & .001 & & \\
\hline Stress management & 1.794 & .392 & .349 & 4.582 & .000 & & \\
\hline Total & & & & & & .697 & .673 \\
\hline
\end{tabular}

Statistical methods: multiple regression analysis.

resilience. Regarding gender, the results of this study found that the resilience in males was higher than in females, similar to the findings of $\mathrm{Li}$ [12], in contrast to Grotberg's report [18] that the divorce can also affect resilience. Faced with the predicament of divorce, the recovery abilities of the female respondents were greater as they were more likely to seek help, share feelings, and indulge in other interactive features, compared to the male respondents, who focused more on the causes of the problem and how to resolve them.

Occupational status was another factor affecting the resilience of CKD patients. We found that patients with an occupation had better resilience, similar to the results of Ross and $\mathrm{Wu}$ [19]. CKD patients and high-risk groups also have special nutritional needs which are particularly important, as shown by Yang [14], for both the prevention and treatment of CKD. Another study by Hollingdale et al. [20] demonstrated that $80 \%$ of $\mathrm{CKD}$ patients were willing to accept restrictions on protein in order to reduce the hazard of ESRD. Self-actualization and stress management are psychological protective factors and best related to resilience [9, 21]. In interviews with CKD patients, Liu et al. [9] and Lamond et al. [21] found that CKD patients admitted that they could not enjoy food like a normal person, and, unfortunately, a degree of freedom was no longer theirs. Even so, they were willing to abide by the dietary restrictions in order to avoid the entrance of dialysis treatment. Lee [22] and Liu [23] have shown that in patients with CKD, the disease itself can cause a great deal of stress. These chronic stresses can lead to depression symptoms. Thus, the future can be enhanced in patients with CKD when the cognitive aspects of adjustment are discussed and hobbies are pursued to reduce stress and allow patients to reconsider their own roles and participate in a group health education to strengthen the ability to adapt to chronic stress. In this way, health education may contribute to the resilience of CKD patients.

The study was limited by time and several research factors. Since it was only a cross-sectional study, there was no long-term followup or continuity to assess patients for resilience at each stage of the kidney disease. Also, we enrolled only those high-risk and CKD patients who utilized the outpatient facilities at our hospital. Therefore, our findings regarding health promotion and resilience cannot be generalized to other hospital outpatient settings.

\section{Conclusion}

In the early $\mathrm{CKD}$ group, the factors affecting resilience included occupation and health-promoting behaviors. However, factors affecting resilience in the pre-ESRD group included gender, occupation, diabetes, and health-promoting behaviors. In the CKD patients, resilience was a significant positive correlation with health promotion behavior. Factors which could effectively predict resilience were gender, occupation, nutrition, self-actualization, and stress levels. Therefore, health education of clinical nurses should focus on health promotion advocacy throughout the life of not only patients, but also their families. We hope that the results of this study can be used as a reference to promote healthy behavior and improve resilience among CKD patients.

\section{References}

[1] N. Chen, W. Wang, Y. Huang et al., "Community-based study on CKD subjects and the associated risk factors," Nephrology Dialysis Transplantation, vol. 24, no. 7, pp. 2117-2123, 2009.

[2] C. P. Wen, T. Y. D. Cheng, M. K. Tsai et al., "All-cause mortality attributable to chronic kidney disease: a prospective cohort study based on 462293 adults in Taiwan," The Lancet, vol. 371, no. 9631, pp. 2173-2182, 2008.

[3] R. Lindqvist, M. Carlsson, and P. O. Sjödén, "Coping strategies and health-related quality of life among spouses of continuous ambulatory peritoneal dialysis, haemodialysis, and transplant patients," Journal of Advanced Nursing, vol. 31, no. 6, pp. 13981408, 2000.

[4] M. L. Chen and N. P. Ku, "Factors associated with quality of life among patients on Hemodialysis," Nursing Research, vol. 6, no. 5, pp. 393-404, 1998.

[5] W. C. Tseng, "A meta-analysis of effect generalizations of protective factors of resilience," Journal of Counseling \& Guidance, vol. 14, pp. 1-35, 2006.

[6] S. S. Hedayati, H. B. Bosworth, M. Kuchibhatla, P. L. Kimmel, and L. A. Szczech, "The predictive value of self-report scales compared with physician diagnosis of depression in hemodialysis patients," Kidney International, vol. 69, no. 9, pp. 1662-1668, 2006.

[7] S. S. Hedayati and F. O. Finkelstein, "Epidemiology, diagnosis, and management of depression in patients with CKD," American Journal of Kidney Diseases, vol. 54, no. 4, pp. 741-752, 2009.

[8] S. C. Yeh, J. L. Sun, L. C. Ma, Y. J. Lin, and H. L. Hsieh, "The depressive symptoms and health related quality of life in 
differential stages of chronic kidney disease patients," Journal of Taiwan Nephrology Nurses Association, vol. 11, no. 3, pp. 16-32, 2012.

[9] L. J. Liu, M. L. Huang, and L. C. Hung, "Coping behaviors and outcomes in Hemodialysis patients," Journal of Taiwan Nephrology Nurses Association, vol. 7, no. 2, pp. 34-49, 2008.

[10] M. Y. Chen, C. C. Chou, H. S. Shiau, E. K. Wang, H. J. Chiou, and J. C. Liang, "The development of Chinese version health promoting lifestyle profile," Chang Gung Nursing, vol. 8, no. 1, pp. 14-24, 1997.

[11] G. M. Wagnild and H. M. Young, "Development and psychometric evaluation of the Resilience Scale," Journal of Nursing Measurement, vol. 1, no. 2, pp. 165-178, 1993.

[12] M. H. Li, "Relationships among stress coping, secure attachment, and the trait of resilience among Taiwanese college students," College Students Journal, vol. 42, no. 2, pp. 312-325, 2008.

[13] W. Margaret, "Resilience in older adults living in Rural, Suburban, and Urban areas," Journal of Rural Nursing and Health Care, vol. 10, no. 2, pp. 45-45, 2010.

[14] W. C. Yang, Development of chronic kidney disease prevention manual plan. Department of Health, the National Health Council in 2006 commissioned a research project, 2007.

[15] N. R. Powe, L. Plantinga, and R. Saran, "Public health surveillance of CKD: principles, steps, and challenges," American Journal of Kidney Diseases, vol. 53, no. 3, supplement 3, pp. S37S45, 2009.

[16] M. Y. Chen, E. K. Wang, and Y. J. Jeng, "Adequate sleep among adolescents is positively associated with health status and health-related behaviors," BMC Public Health, vol. 6, article 59, 2006.

[17] A. S. Mary, M. M. Madonna, A. B. Sharon, and A. J. Christopher, "A resilience intervention in African American adults with type II diabetes: a pilot study of efficacy," Diabetic Educator, vol. 35, no. 2, pp. 274-284, 2009.

[18] E. H. Grotberg, Tapping your Inner Strength, Oakland, Calif, USA, 1999.

[19] C. E. Ross and C. Wu, "The links between education and health," American Sociological Review, vol. 60, no. 5, pp. 719-745, 1995.

[20] R. Hollingdale, D. Sutton, and K. Hart, "Facilitating dietary change in renal disease: investigating patients' perspectives," Journal of Renal Care, vol. 34, no. 3, pp. 136-142, 2008.

[21] A. J. Lamond, C. A. Depp, M. Allison et al., "Measurement and predictors of resilience among community-dwelling older women," Journal of Psychiatric Research, vol. 43, no. 2, pp. 148$154,2008$.

[22] L. C. Lee, "Theoretical basis for medical counseling to diseases adapt the theory," Counseling and Guidance, vol. 250, no. 2, pp. 42-49, 2006.

[23] J. N. Liu, "Social-economic status, general health status, health behaviors and community adult population depression relationship," Taiwan Journal of Public Health, vol. 38, no. 4, pp. 300-311, 2009. 


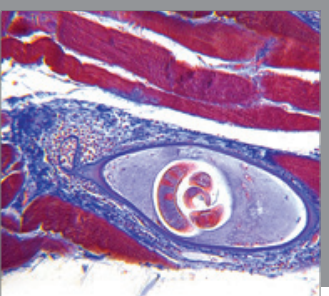

Gastroenterology

Research and Practice
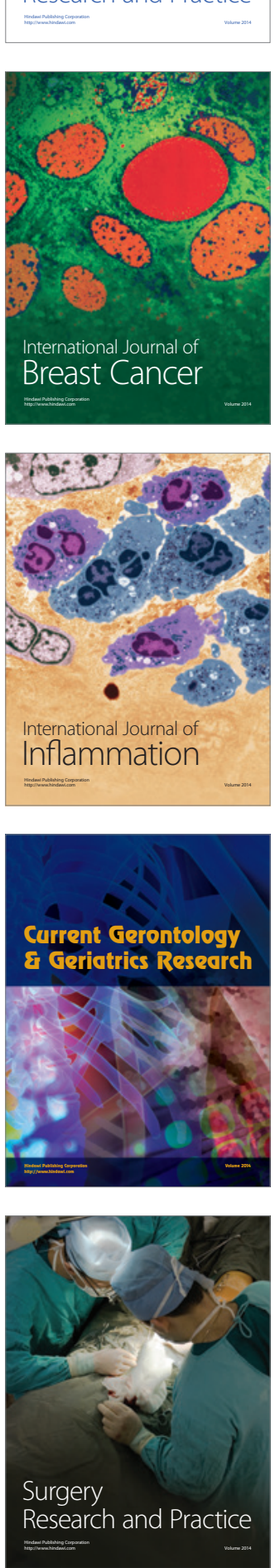

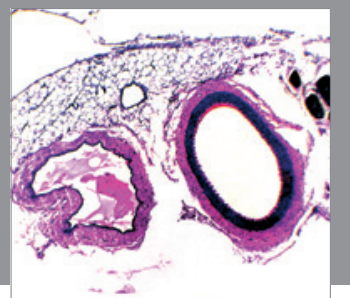

International Journal of Hypertension
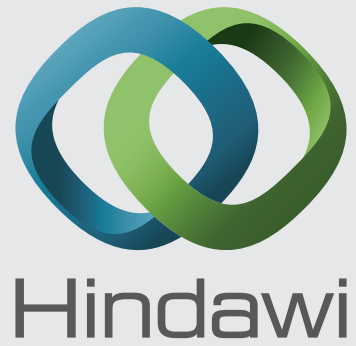

Submit your manuscripts at http://www.hindawi.com
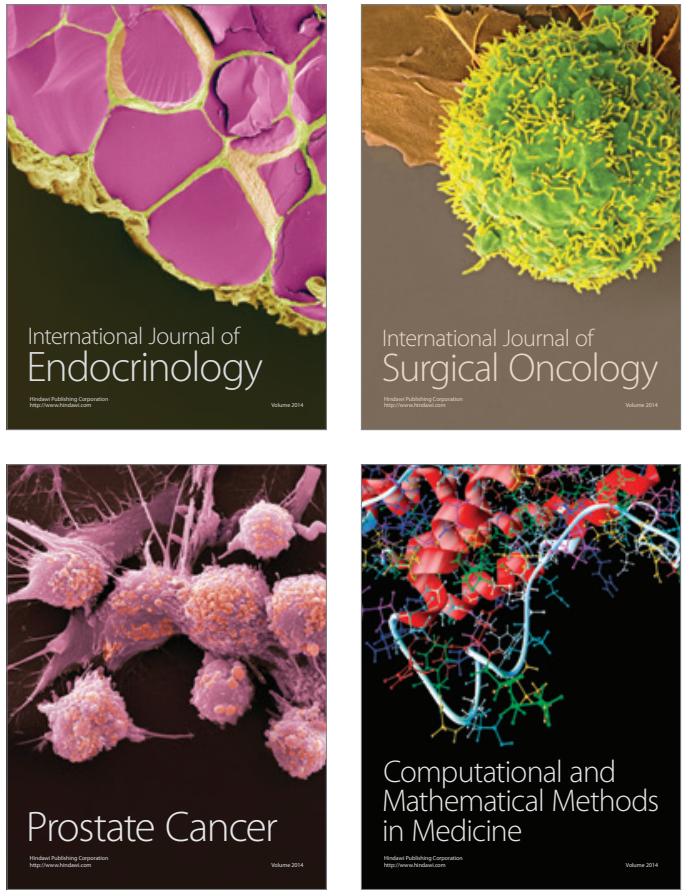
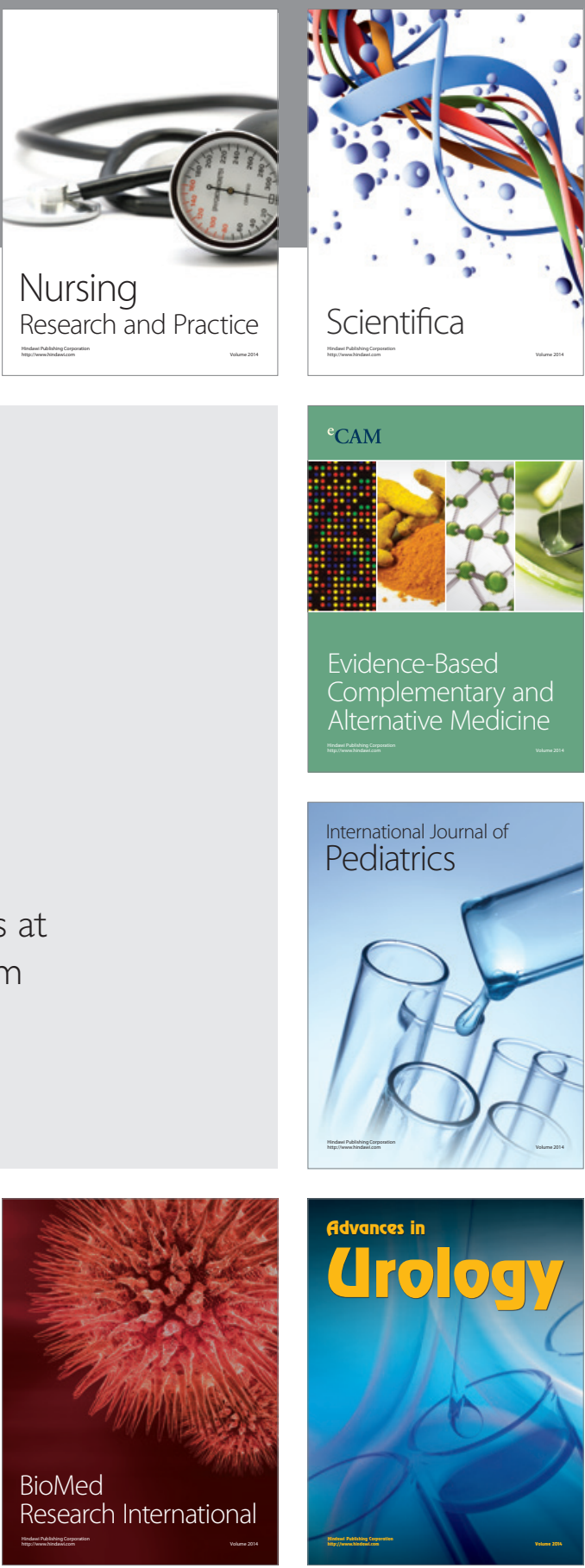

Nursing

Research and Practice

Scientifica

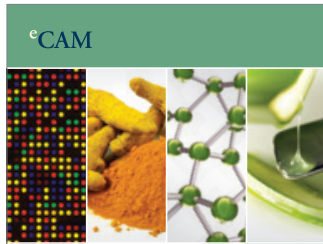

Evidence-Based

Complementary and Alternative Medicine
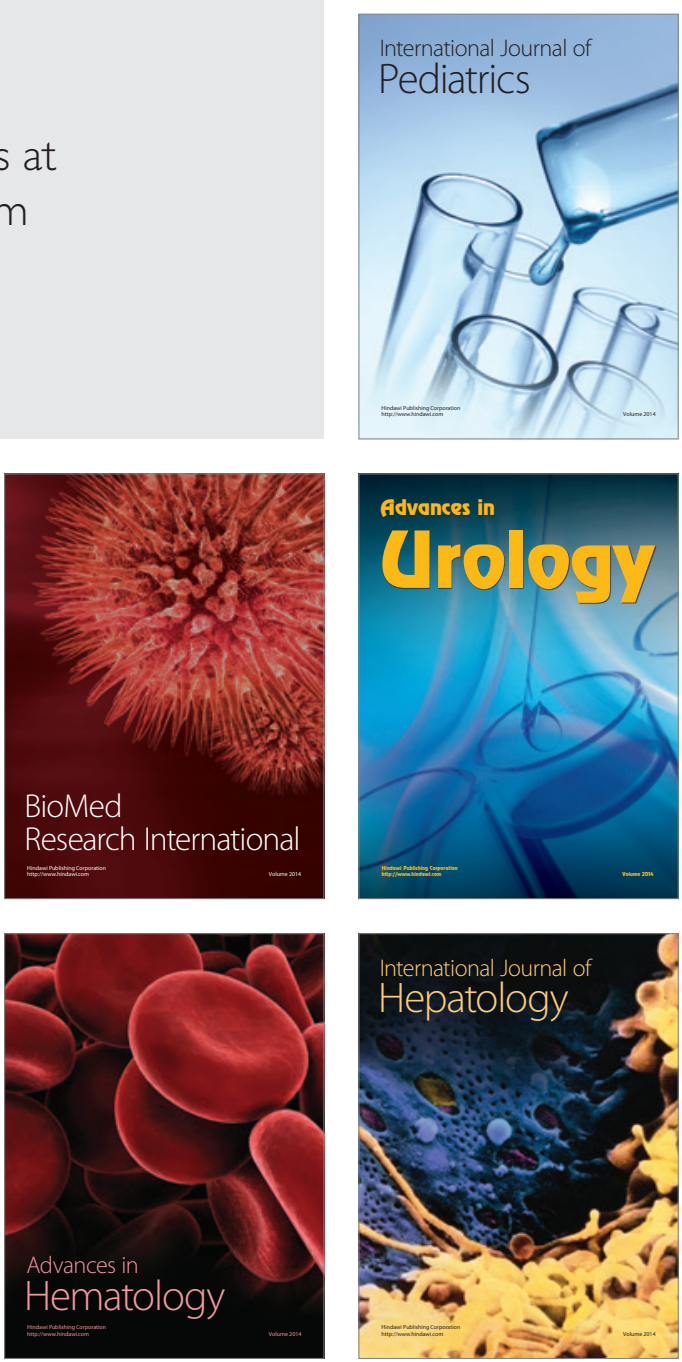